\title{
A soluble activator that favors the ex vivo expansion of $\mathrm{CD8}{ }^{+} \mathrm{CD} 27^{+} \mathrm{T}$ cells
}

\author{
Esther I. Matus, ${ }^{1,2}$ Amanda Sparkes, ${ }^{1}$ and Jean Gariépy ${ }^{1,2,3}$ \\ ${ }^{1}$ Sunnybrook Research Institute, ${ }^{2}$ Department of Medical Biophysics, and ${ }^{3}$ Department of Pharmaceutical Sciences, \\ University of Toronto, Toronto, Canada, USA.
}

\begin{abstract}
Adoptive cell therapy involves the infusion of tumor-reactive $T$ cells into patients with cancer to provide antitumor immunity. The ex vivo expansion and differentiation of such T cells are key parameters that affect their therapeutic potential. Human $\mathrm{T}$ cells are presently expanded in culture through the use of anti-CD3 and anti-CD28 mAbs immobilized on beads, expressed on cells, or assembled in the context of soluble antibody complexes. Here we report the design of a small, bispecific single-chain variable fragment construct agonizing both $\mathrm{CD} 3$ and $\mathrm{CD} 28$ pathways. This soluble T cell expansion protein, termed T-CEP, activates, expands, and differentiates human T cells ex vivo at concentrations in the femtomolar range. Importantly, T-CEP promotes the preferential growth of human $\mathrm{CD8} 8^{+} \mathrm{T}$ cells over the course of 12 days in comparison with methods involving immobilized anti-CD3 mAb/soluble anti-CD28 mAb or soluble anti-CD3/CD28 mAb complexes. The differentiation profile of the resulting human $\mathrm{T}$ cell population is also singularly affected by T-CEP, favoring the expansion of a preferred $\mathrm{CD8}{ }^{+} \mathrm{CD} 27^{+} \mathrm{T}$ cell phenotype. The activity profile of T-CEP on human $\mathrm{T}$ cells ex vivo suggests its use in generating human $\mathrm{T}$ cell populations that are more suited for adoptive cell therapy.
\end{abstract}

Conflict of interest: The authors have declared that no conflict of interest exists.

Copyright: (c) 2020, Matus et al. This is an open access article published under the terms of the Creative Commons Attribution 4.0 International License.

Submitted: June 12, 2020

Accepted: October 15, 2020

Published: November 19, 2020

Reference information: /CI Insight. 2020;5(22):e141293.

https://doi.org/10.1172/jici.

insight.141293.

\section{Introduction}

Adoptive cell therapy (ACT) regroups cell-based clinical approaches typically exemplified by lymphocytes with antitumor activity being transferred into patients to eliminate specific cancer cells (1). Such approaches have been successful in treating hematological malignancies, metastatic melanoma, and metastatic breast cancer (2-4). Depending on the type of malignancy, treatment may be carried out using a patient's own tumor-infiltrating lymphocytes (TILs), by designing chimeric antigen receptor (CAR) T cells, or by employing genetically modified $\mathrm{T}$ cells. These lymphocytes, and in particular highly functional human $\mathrm{T}$ cells, must all be expanded ex vivo before infusion into a patient (5-7), a key step that requires overcoming challenges associated with expanding such cells to generate clinically effective doses (7). Important steps for the ex vivo activation, expansion, and survival of human T cells include a TCR-mediated activation signal, a costimulatory signal, and signaling through cytokines (8). In vitro polyclonal T cell activation is generally accomplished through the use of agonistic antibodies targeting CD3 and CD28 providing both TCR activation and costimulatory signals, respectively, with appropriate cytokines being supplemented (5).

There are several clinically important criteria linked to the success of using human T cells for ACT. First, CD8 ${ }^{+} \mathrm{T}$ cells are favored in ACT due to their cytolytic activity (9), although transferred CD4 ${ }^{+} \mathrm{T}$ cells also display the potential to enhance $\mathrm{CD} 8^{+} \mathrm{T}$ cell-mediated tumor rejection (10). A second key parameter is the differentiation state of the resulting $\mathrm{T}$ cell product expanded ex vivo. Specifically, $\mathrm{T}$ cell differentiation events take place during their expansion, which can ultimately lead to a loss of crucial ACT characteristics required for their optimal persistence and function in vivo $(11,12)$. Less differentiated $\mathrm{T}$ cells are considered more desirable for ACT, which can be distinguished based on the surface expression of known markers for naive T cells $(\mathrm{Tn})$, stem cell memory T cells (Tscm), and central memory T cells (Tcm) as opposed to more differentiated effector memory $\mathrm{T}$ cells (Tem) and terminally differentiated $\mathrm{T}$ cells (Temra) $(13,14)$. $\mathrm{T}$ cell activation, proliferation, and differentiation through agonizing both CD3 and CD28 pathways in vitro can expand cells in a unique manner based on how both signals are presented to human $\mathrm{T}$ cells and the cytokines that are provided. Studies have now shown that different expansion methods and the modification of such methods can lead to T cells displaying more desirable phenotypes (15-17). Parameters such as ligand density (18), mechanical forces $(19,20)$, strength of the interaction $(21)$, and duration of the signal that activates 
human T cells affect the outcome of the ACT response (22). Triggering T cell activation through different formats of signal delivery is therefore expected to skew the final $\mathrm{T}$ cell phenotype.

In this report, we have engineered a highly potent, monomeric protein that expands human $\mathrm{T}$ cells ex vivo when added as a soluble factor at low concentrations. The potency of this $\mathrm{T}$ cell expansion protein (termed T-CEP) was compared with an established protocol where an immobilized agonistic anti-CD3 $\mathrm{mAb}$ is combined with a soluble anti-CD28 $\mathrm{mAb}$. T-CEP was also compared with a commercially available soluble T cell activator that targets both human CD3 and CD28 in the format of a combined solution of monospecific tetrameric antibody complexes (TACs). T-CEP was shown to engage both CD3 and CD28 on human $\mathrm{T}$ cells. The concomitant triggering of both signaling pathways led to a high level of $\mathrm{T}$ cell proliferative activity. Furthermore, T-CEP demonstrated an improved ability to expand CD8 $8^{+}$human $\mathrm{T}$ cell populations, exhibiting a less differentiated $\mathrm{T}$ cell phenotype that is clinically linked to more successful ACT outcomes in patients.

\section{Results}

\section{Design and production of T-CEP}

A $60 \mathrm{kDa}$ soluble T-CEP was designed by fusing 2 distinct single chain variable fragments (scFvs) that respectively bind to human CD3 and human CD28 and act as agonists in activating both signaling pathways (Figure 1A). These selected scFv sequences have independently been shown to agonize CD3 and CD28, respectively, and accordingly activate human $\mathrm{T}$ cells. These scFvs were linked using a short flexible spacer (SSGSGGGGSGGGGSGGGGS), similar to previously described linkers (23). A 6-histidine tag was added at the C-terminus of the construct for purification purposes and for detecting the construct (Figure 1A). Of note, 2 T-CEP constructs were originally built to assess whether the orientation (i.e., the anti-CD28 scFv at the C-terminus or the N-terminus of the construct) had an impact on their functional properties. The construct as depicted in Figure $1 \mathrm{~A}$, with the scFv targeting CD28 at the N-terminus, and the CD3 scFv placed at its C-terminus, was ultimately chosen as the lead compound, based on higher expression yields and being more potent in terms of expanding $\mathrm{T}$ cells (results not shown). T-CEP was expressed as a secreted, soluble protein produced in Expi293F cells (Expi293 expression system) and purified using immobilized metal affinity chromatography. Its purity was confirmed by SDS-PAGE and Western blot analysis, migrating as a $60 \mathrm{kDa}$ band, corresponding to the expected molecular weight of T-CEP based on its amino acid sequence (Figure 1B).

Based on its structure, T-CEP is an agent that is designed to engage signals for TCR activation and costimulation at a molar ratio of $1: 1$. The other currently available commercial soluble $\mathrm{T}$ cell activator (STEMCELL Technologies) delivers these signals in the form of soluble, monospecific TACs, complexes of agonistic mAbs against CD3 or CD28 noncovalently associated together through their Fc domains (24). The prepared TACs are then combined in one solution at a 1:1 ratio of anti-CD3 TACs and anti-CD28 TACs, resulting in an expected component ratio of 1:1.

\section{T-CEP binds to the human CD3 and CD28 extracellular domains}

The binding of T-CEP to the extracellular domains of CD3 and CD28 was confirmed by surface plas-

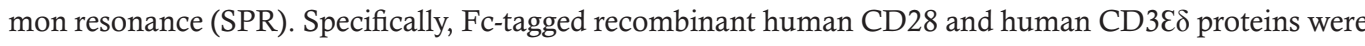
immobilized on a protein G-modified chip, and increasing concentrations of T-CEP were flown over each immobilized target. Resulting sensorgrams were analyzed (Biacore T200 evaluation software) to calculate binding kinetic parameters (fitted to a Langmuir 1:1 binding model, Figure 2A and Table 1). T-CEP was shown to bind tightly to both CD3 and CD28 targets with equilibrium $K_{D}$ s of $0.48 \mathrm{nM}$ and $0.24 \mathrm{nM}$, respectively. The dissociation rate $\left(\mathrm{k}_{\text {off }}\right)$ of T-CEP binding to CD3 was $4.3 \times 10^{-2} / \mathrm{s}, 2$ orders of magnitude greater than the dissociation of T-CEP binding to CD28. T-CEP binding to CD3E $\delta$ had a lower $K_{D}$ (higher affinity), higher $\mathrm{k}_{\mathrm{on}}$, and faster dissociation rate relative to anti-CD3 mAbs binding to CD3E $\delta$ (25). A relatively fast $\mathrm{k}_{\text {off }}$ represents a key factor in efficiently activating $\mathrm{T}$ cells, as it contributes to the turnover of TCR-MHC-peptide interactions (26).

Binding to both targets simultaneously was analyzed using an enzyme-linked immunosorbent assay (ELISA). Consistent with the SPR results, both recombinant proteins bound T-CEP alone as evident by a positive signal for FC-tagged recombinant $\mathrm{CD} 3 E \delta$ and $\mathrm{CD} 28$ individually. In contrast, no signal was observed in the case of an Fc-matched control (Supplemental Figure 1; supplemental material available online with this article; https://doi.org/10.1172/jci.insight.141293DS1). To determine whether T-CEP 
A

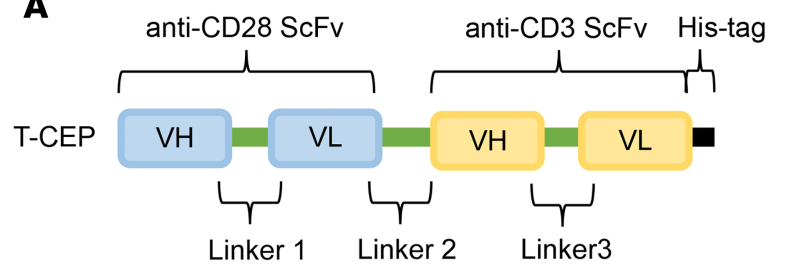

Linker 1

Linker 2

Linker 3

\section{GGGGSGGGGSGGGGS SSGSGGGGSGGGGSGGGGS GGSGGSGGSGGSGG}

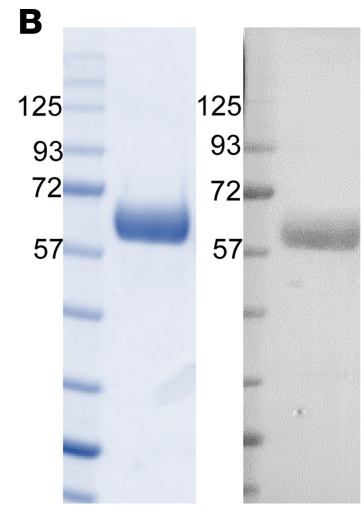

Figure 1. Design and purification of T-CEP. (A) Diagram depicting the structure of T-CEP, a T cell expansion protein T-CEP is a bispecific agent composed of an N-terminal agonistic CD28-targeting scFv connected by a short flexible linker (Linker 2) to an agonistic CD3-binding scFv. Both scFvs are further defined as linear assemblies of variable heavy (VH) and variable light (VL) chains. A histidine tag (6x His) was inserted at the C-terminus of T-CEP for purification and detection purposes. (B) Recombinant T-CEP was produced in Expi293F cells and purified by Ni-NTA affinity chromatography. Its purity was confirmed by SDS-PAGE (left panel; Coomassie staining) and by Western blot (right panel; detected using an anti-His tag antibody). The protein migrates as an approximately $60 \mathrm{kDa}$ band.

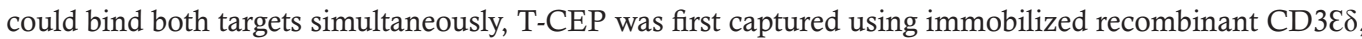
then detected using recombinant $\mathrm{CD} 28 . \mathrm{CD} 3 \varepsilon \delta$ - $\mathrm{Fc}$ or the $\mathrm{Fc}$ control was first coated onto an ELISA plate and T-CEP subsequently added to wells, followed by incubation with biotinylated human CD28-Fc extracellular domain and detection with streptavidin-HRP. A positive signal was observed only in wells that contained both CD3E $\delta$-Fc and T-CEP, indicating that T-CEP is able to bind both targets at once. In contrast, wells coated with an Fc control or lacking T-CEP did not bind biotinylated CD28-Fc (Figure 2B).

\section{Functional characterization of T-CEP on human T cells}

$T$-CEP induces the proliferation of both human $C D 4^{+}$and $C D 8^{+} T$ cells at very low concentrations. To determine the optimal working concentration of T-CEP, T cells isolated from human PBMCs were stained with carboxyfluorescein succinimidyl ester (CFSE) (a cell proliferation tracer) and stimulated with T-CEP for 5 days over a range of T-CEP concentrations ( $50 \mathrm{pg} / \mathrm{mL}$ up to $10 \mu \mathrm{g} / \mathrm{mL}$ ). Their proliferative activity, as evidenced by a loss in CFSE signal, was analyzed by flow cytometry (results not shown). Comparable $\mathrm{T}$ cell proliferative activity by T-CEP was noted for concentrations as low as $500 \mathrm{pg} / \mathrm{mL}$. However, for all subsequent studies, a T-CEP concentration of $10 \mathrm{ng} / \mathrm{mL}(170 \mathrm{fM}$ ) was selected as it consistently yielded maximal $\mathrm{T}$ cell proliferation (Figure 3A). Interestingly, the concentration of soluble T-CEP required to cause a full expansion of human T cells ex vivo was 150-fold less (in g/L) than required for TACs (when used per manufacturer instructions, $\sim 1.5 \mu \mathrm{g} / \mathrm{mL}, \sim 2.5 \mathrm{pM}$ ). This T-CEP concentration was also far less than the optimal doses of i $\alpha \mathrm{CD} 3(5 \mu \mathrm{g} / \mathrm{mL})$ and s $\alpha \mathrm{CD} 28(1 \mu \mathrm{g} /$ $\mathrm{mL}$ ) $\mathrm{mAbs}$. As expected, unstimulated $\mathrm{T}$ cells did not proliferate while anti-CD3 without costimulation led to a much-reduced level of both $\mathrm{CD} 4^{+}$and $\mathrm{CD} 8^{+}$human $\mathrm{T}$ cell proliferation. Over 5 donors, significantly greater proliferation was induced after 5 days using T-CEP relative to TACs in CD $4^{+} \mathrm{T}$ cells $(P<0.05)$, and $\mathrm{CD} 8^{+} \mathrm{T}$ cells $(P<0.05)$, demonstrating that on average $87.8 \%$ of the $\mathrm{CD} 4^{+}$and $80.9 \%$ of the $\mathrm{CD} 8^{+} \mathrm{T}$ cells had undergone proliferation according to CFSE levels (Figure 3B).

Cytokines released into the culture medium by activated human $\mathrm{CD}^{+} \mathrm{T}$ cells were measured at day 5 , as shown by cytokine secretion profiles (Figure 3C). Both T-CEP $(10 \mathrm{ng} / \mathrm{mL})$ and TACs $(\sim 1.5 \mu \mathrm{g} / \mathrm{mL})$ induced the production of IL-2 at higher levels than when T cells were stimulated with $i \alpha \mathrm{CD} 3$ and $i \alpha \mathrm{CD} 3$ with $\mathrm{s} \alpha \mathrm{CD} 28$ mAbs. T-CEP also showed high levels of IFN- $\gamma$ and TNF- $\alpha$ secretion. Across all 5 donors, IL-2, IFN- $\gamma$, and TNF- $\alpha$ secretion by T-CEP was significantly increased relative to i $\alpha C D 3$, yielding the highest level of TNF- $\alpha$ secretion in each donor. The high secretion of cytokines 5 days after stimulation relative to the other methods demonstrates the superior ability of T-CEP to induce early activation and proliferation at fM concentrations.

T-CEP leads to the activation and expansion of T cells over the course of 12 days. T cells used for $\mathrm{ACT}$ are required to undergo a rapid expansion phase lasting 12-14 days before reinfusion into the patient (1). Human $\mathrm{CD}^{+} \mathrm{T}$ cells isolated from PBMCs of 5 healthy donors were expanded over the course of 12 days after a single stimulation, with IL-2 being added to the medium to further aid in cell expansion and activation ex vivo. Cells were 


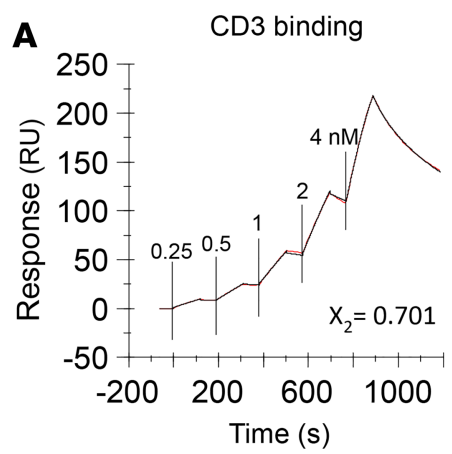

B

Bispecific Binding
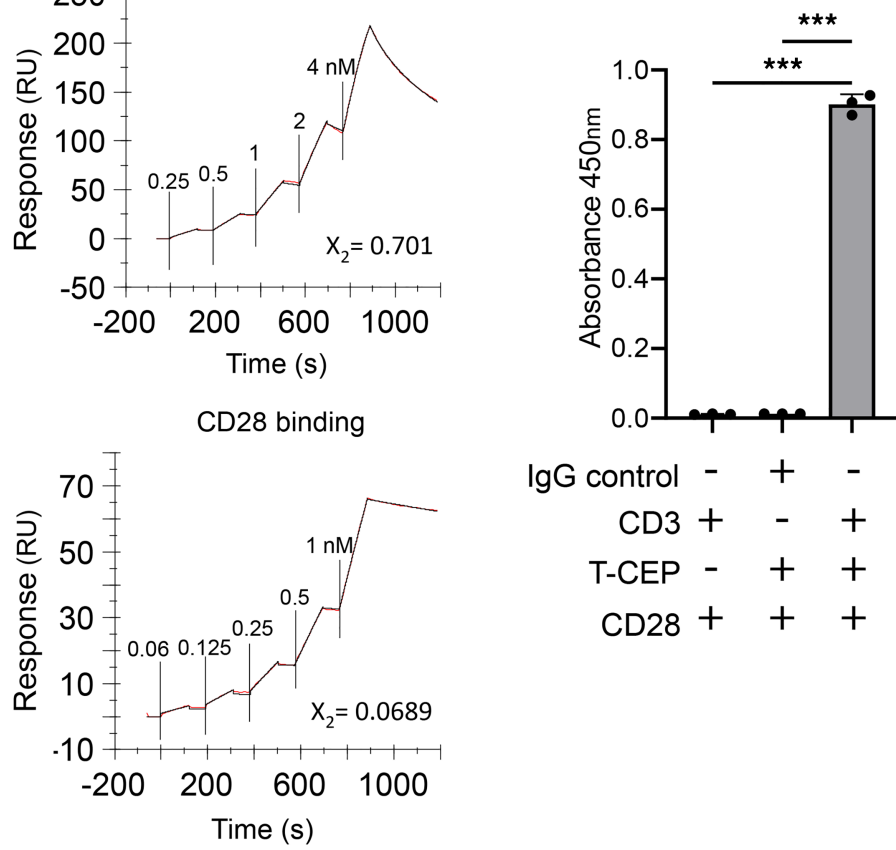

Figure 2. Characterization of T-CEP binding to human CD3 and human CD28 extracellular domains. (A) Surface plasmon resonance (SPR) sensorgrams depicting the binding of T-CEP to recombinant human Fc-tagged CD3 $\varepsilon \delta$ and recombinant human Fc-tagged CD28 over a range of T-CEP concentrations to calculate kinetic parameters using the 1:1 binding model using Biacore evaluation software. (B) Enzyme-linked immunosorbent assay (ELISA) confirming the binding of soluble T-CEP to plate-bound recombinant human CD3-Fc or an IgC control. The CD3-bound T-CEP was subsequently detected using a biotinylated recombinant human CD28-Fc construct followed by a streptavidin-HRP conjugate ( $n=3$, 1-way ANOVA with a Tukey's multiple-comparison test). ${ }^{* *} P<0.001$.

transferred to G-Rex plates 3 days into the 12-day expansion stage. Every subsequent 3 days, aliquots were taken from duplicate wells to record the number of viable $\mathrm{T}$ cells present. $\mathrm{T}$ cells from the 5 donors were stimulated with T-CEP (10 ng/mL; $170 \mathrm{fM})$ or soluble TACs $(25 \mu \mathrm{L} / \mathrm{mL}, \sim 1.5 \mu \mathrm{g} / \mathrm{mL})$ or with i $\alpha \mathrm{CD} 3$ with or without $\mathrm{s} \alpha \mathrm{CD} 28$ (Figure 4A). The highest levels of total $\mathrm{T}$ cell expansion were observed on day 12, when $\mathrm{T}$ cells were treated ex vivo with soluble expansion methods. Importantly, T-CEP accounted for the highest $\mathrm{T}$ cell expansion in 4 of 5 PBMC donors (Supplemental Figure 2). As expected, unstimulated T cells did not expand, while T cells treated with i $\alpha \mathrm{CD} 3$ alone displayed a reduced level of T cell expansion relative to methods that included CD28 costimulation. All these approaches, however, yielded lower average levels of expansion than by T-CEP, with significant increases observed for T-CEP relative to immobilized methods $(P<0.05)$ (Figure 4A).

$\mathrm{T}$ cells were further analyzed by flow cytometry to monitor the expansion of $\mathrm{CD}^{+}$and $\mathrm{CD} 8^{+} \mathrm{T}$ cell subsets over 12 days for the 5 donors, relative to the starting number of $\mathrm{CD}^{+}$or $\mathrm{CD} 8^{+} \mathrm{T}$ cells before stimulation (Figure 4B). Treatment with TAC induced the highest level of human $\mathrm{CD}^{+} \mathrm{T}$ cell expansion after 12 days (mean: 48-fold, range: 34 - to 67-fold). This increase was significantly greater than observed for i $\alpha \mathrm{CD} 3$ alone (mean: 8-fold, range: 1 - to 13 -fold) $(P<0.0001)$, i $\alpha$ CD3 with s $\alpha$ CD28 (mean: 15 -fold, range: 4 - to 20 -fold) $(P$ $<0.001$ ), and T-CEP (mean: 27-fold, range: 13 - to 45 -fold) $(P<0.05)$. In contrast, T-CEP favored the expansion of $\mathrm{CD}^{+} \mathrm{T}$ cells, with the highest $\mathrm{CD} 8^{+} \mathrm{T}$ cell expansion in each of the 5 PBMC donors, resulting in a 317-fold mean expansion rate (range: 222-to 576-fold). This level of expansion was significantly greater than with i $\alpha$ CD3 alone (mean: 119-fold, range: 30- to 208-fold) $(P<0.005)$ or after stimulation with i $\alpha C D 3$ with s $\alpha \mathrm{CD} 28$ (mean: 173-fold; range, 116- to 224-fold) $(P<0.05)$, while also trending toward significance compared with stimulation with TACs $(P=0.06)$ (mean: 208 -fold, range: 141 - to 360 -fold).

To further assess the extent of $\mathrm{CD}^{+}$and $\mathrm{CD}^{+} \mathrm{T}$ cell subsets' expansion after 12 days under each expansion condition, we determined by flow cytometry the percentages of $\mathrm{CD} 4^{+}$and $\mathrm{CD} 8^{+} \mathrm{T}$ cell populations relative to the total population of viable lymphocytes recovered from the 5 donors (Figure 4C). Comparing T-CEP with other conditions that provide costimulation indicated that T-CEP favored the expansion of $\mathrm{CD}^{+} \mathrm{T}$ cells over $\mathrm{CD} 4^{+} \mathrm{T}$ cells, and a similar ratio of $\mathrm{T}$ cells was produced when treated with 
Table 1. Summary of T-CEP binding kinetics parameters calculated from SPR sensorgrams

\begin{tabular}{|c|c|c|c|}
\hline Antigen & $k_{\text {on }} 10^{7}\left[M^{-1} s^{-1}\right]$ & $k_{\text {off }} 10^{-2}\left[s^{-1}\right]$ & $K_{D}[\mathrm{nM}]$ \\
\hline CDЗE & 8.9 & 4.3 & 0.48 \\
\hline CD28 & 0.11 & 0.027 & 0.24 \\
\hline
\end{tabular}

a conventional method of i $\alpha \mathrm{CD} 3$ with s $\alpha \mathrm{CD} 28$. In contrast, T cell treatment with TACs led to a significantly reduced percentage of $\mathrm{CD}^{+} \mathrm{T}$ cells $(P<0.0001)$ and an increased percentage of $\mathrm{CD} 4^{+} \mathrm{T}$ cells $(P<$ 0.0001). Before stimulation, the $\mathrm{CD} 4^{+} / \mathrm{CD}^{+}$ratios of $\mathrm{T}$ cells purified from healthy donor PBMCs were between 2.1 and 2.7. After stimulation with T-CEP, the $\mathrm{CD} 4^{+} / \mathrm{CD} 8^{+}$ratio ranged from 0.15 to 0.3 .

The levels of activation markers CD25 and CD38 on human $\mathrm{CD} 4^{+}$and $\mathrm{CD} 8^{+} \mathrm{T}$ cells from the 5 donors were monitored by flow cytometry at specific time points during the 12-day expansion period (Figure 5A). The increase in median fluorescence intensity (MFI) of CD25 expression peaked on day 3 and on day 6 for CD38. $\mathrm{T}$-CEP induced the highest average level of activation markers on the peak day in the $\mathrm{CD} 8^{+}$and $\mathrm{CD} 4^{+} \mathrm{T}$ cell populations. Specifically, the observed CD25 MFI values on day 3 were highest in the T-CEP-treated CD4 ${ }^{+} \mathrm{T}$ cell population (mean MFI 1577), which was significant relative to the same population of $\mathrm{T}$ cells expanded with either i $\alpha$ CD3 with s $\alpha C D 28$ (MFI 640, $P<0.05$ ) or i $\alpha$ CD3 (MFI 629, $P<0.05$ ), though not significant when compared with TACs (MFI 1463). Again, the average CD25 MFI values on day 3 were highest in the T-CEP-treated $\mathrm{CD}^{+}$population (mean MFI 2558), although only significantly higher than i $\alpha \mathrm{CD} 3$ with s $\alpha C D 28$ (MFI 1368, $P<0.05$ ), not i $\alpha$ CD3 (MFI 1427) alone or TACs (MFI 1463) treated CD8 ${ }^{+}$cell populations. In both $\mathrm{CD}^{+}$and $\mathrm{CD} 8^{+} \mathrm{T}$ cells, the overall trend in $\mathrm{CD} 38$ expression showed highest $\mathrm{CD} 38 \mathrm{MFI}$ values on day 6 , with the highest average values in the 5 donors being observed after T-CEP stimulation. However, this trend was not statistically significant. On day 12 the levels of both activation markers were comparable to that before stimulation, regardless of the expansion method used or the activation marker being monitored.

The surface expression of exhaustion markers programmed cell death protein 1 (PD-1) and lymphocyte activation gene 3 (LAG-3) coexpressed on $\mathrm{CD}^{+}$and $\mathrm{CD} 8^{+} \mathrm{T}$ cells was analyzed by flow cytometry for each expansion condition (Figure $5 \mathrm{~B}$ ). The percentage of $\mathrm{CD} 4^{+}$and $\mathrm{CD} 8^{+} \mathrm{T}$ cells coexpressing these markers peaked on day 3 for all expansion methods tested. In 5 donors, the day 3 coexpression was significantly higher in $\mathrm{CD}^{+}$and $\mathrm{CD}^{+} \mathrm{T}$ cells stimulated with T-CEP in both $\mathrm{CD} 4^{+} \mathrm{T}$ cells (mean: $36.6 \%$ ) and $\mathrm{CD} 8^{+} \mathrm{T}$ cells $(50.9 \%)$ as compared with all the other tested expansion methods (CD4+ $\mathrm{T}$ cells: $\mathrm{i} \alpha \mathrm{CD} 35.5 \%$, i $\alpha \mathrm{CD} 3$ with s $\alpha \mathrm{CD} 28$ 16.1\%, TACs $14.0 \%$; CD8 ${ }^{+}$T cells: i $\alpha$ CD3 $16.2 \%$, i $\alpha$ CD3 with s $\alpha C D 2824.7 \%$, TACs $29.9 \%$ ). However, this expression pattern returned to preactivation levels by day 9 and day 12 following each stimulation method.

\section{Stimulation with T-CEP leads to distinct human T cell phenotypic differentiation}

The differentiation patterns of human $\mathrm{T}$ cells from 5 donors were analyzed for the 12-day period. In particular, the expression levels of CD45RA and CD27 were monitored on $\mathrm{CD}^{+}$and $\mathrm{CD}^{+}$cells to provide an estimate of the differentiation state of these $\mathrm{T}$ cell subsets (Figure 6A). Specifically, CD27 plays a role in $\mathrm{T}$ cell activation and differentiation, and its expression has been associated with in vivo persistence of $\mathrm{T}$ cells $(2$, 27), while the loss of CD27 expression generally indicates late or terminal differentiation (28). Meanwhile, CD45RA is expressed on early Tn and Tscm cell subsets, and its expression is lost upon differentiation into $\mathrm{Tcm}$ and Tem cells. This marker is then reexpressed upon differentiation into a late-stage Temra subset (29, 30). Therefore, it is expected that $\mathrm{T}$ cell subsets would display the following expression pattern of these 2 markers as follows: CD45RA ${ }^{+} \mathrm{CD} 27^{+}<\mathrm{CD} 45 \mathrm{RA}^{-} \mathrm{CD} 27^{+}<\mathrm{CD}^{2} 5 \mathrm{RA}^{-} \mathrm{CD} 27^{-}<\mathrm{CD}^{-} 5 \mathrm{RA}^{+} \mathrm{CD}_{27} 7^{-}$going from least to furthest differentiated states. After 12 days of expansion ex vivo, the T-CEP-treated human CD4 ${ }^{+}$ $\mathrm{T}$ cell population in each donor exhibited relatively low percentages of the more differentiated populations (Figure 6B). Over the 5 donors, the average percentage of $\mathrm{CD}_{5} 5 \mathrm{RA}^{+} \mathrm{CD} 27^{-}$cells in the $\mathrm{CD}^{+}$population was the lowest after T-CEP expansion (1.5\%), while the CD45RA-CD27- population was also lower than all other tested methods (21.6\%). T-CEP was the only method to significantly reduce the average CD45RA $\mathrm{CD}_{27}$ population compared with i $\alpha \mathrm{CD} 3$ alone $(44.0 \%)(P<0.05)$. Meanwhile, the $\mathrm{CD} 45 \mathrm{RA}^{-} \mathrm{CD} 27^{+}$phenotype in the $\mathrm{CD}^{+} \mathrm{T}$ cell population was significantly increased when treated with T-CEP as compared with $\mathrm{T}$ cells treated with i $\alpha \mathrm{CD} 3$ alone $(P<0.001)$ and i $\alpha \mathrm{CD} 3$ with s CD28 $(P<0.05)$. This increase in $\mathrm{CD} 4 \mathrm{RA}^{-} \mathrm{CD} 27^{+}$phenotype was also seen following treatment with TACs but to a lesser extent (Figure 6B). 

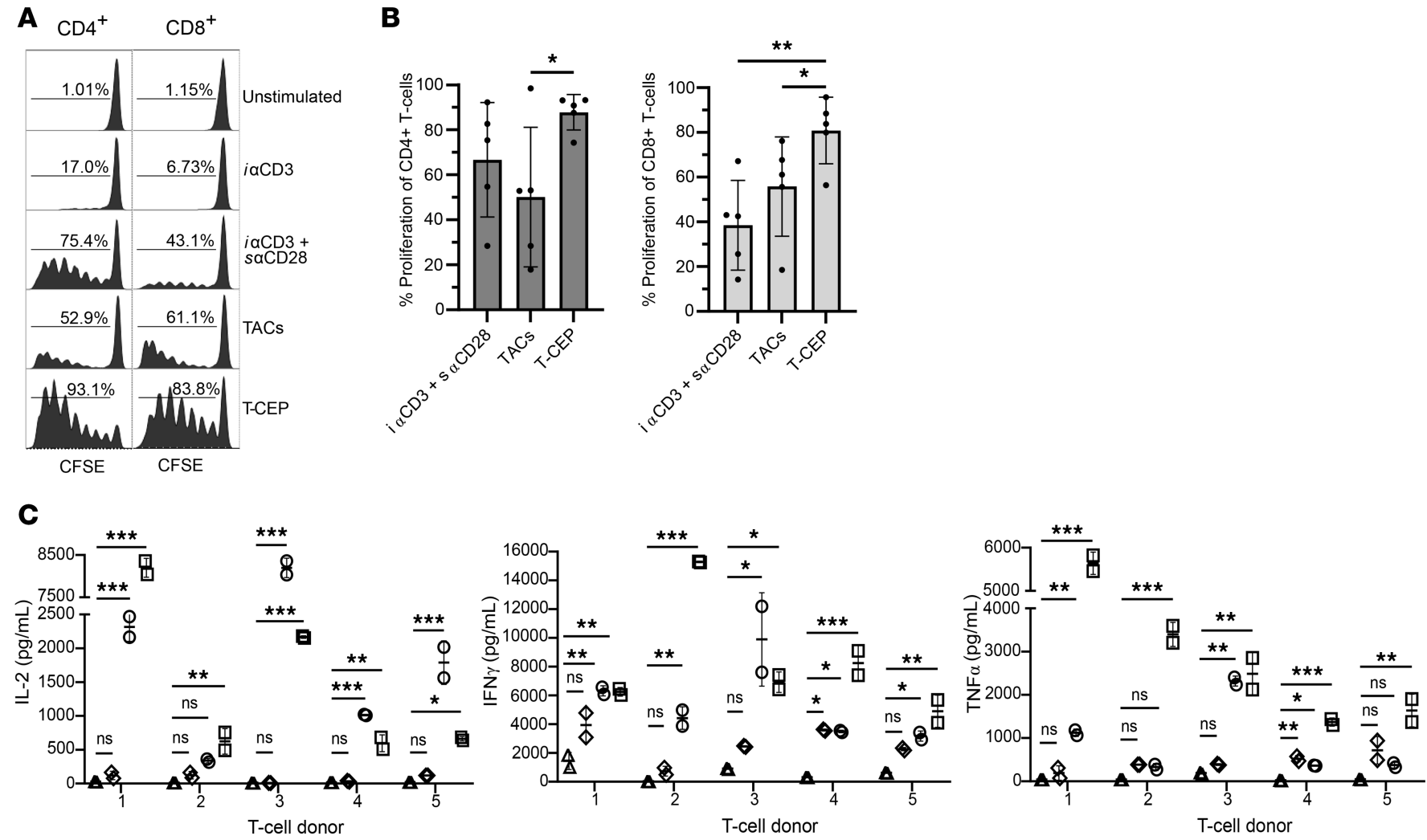

Figure 3. Low concentrations of T-CEP promote the ex vivo activation and proliferation of human T cells. (A) Representative CFSE profiles depicting the proliferation status of human T cells after a 5 -day exposure to T cell-expanding conditions, without added cytokines. Immobilized anti-CD3 (i $\alpha$ CD3) and soluble $\alpha \mathrm{CD} 28$ (s $\alpha \mathrm{CD} 28$ ) agonistic mAbs were used at working concentrations of $5 \mu \mathrm{g} / \mathrm{mL}$ and $1 \mu \mathrm{g} / \mathrm{mL}$, respectively, while the final concentration of TACs in wells was approximately $1.5 \mu \mathrm{g} / \mathrm{mL}$. T-CEP was dispensed into wells to a final concentration of $10 \mathrm{ng} / \mathrm{mL}(170 \mathrm{fM})$. Similar T cell expansion profiles were observed from PBMCs isolated from 5 donors. (B) The early proliferative capabilities of T-CEP as measured by CFSE (day 5 after stimulation). T-CEP stimulation led to consistently elevated proliferation levels of $\mathrm{CD} 4^{+}$and $C D 8^{+} T$ cells, where both $C D 4^{+}$and $C D 8^{+} T$ cell proliferation levels were significantly higher than recorded for cells treated with TACs or i $\alpha \mathrm{CD} 3$ with $\mathrm{s} \alpha \mathrm{CD} 28$ ( $n=5$ donors, 1-way repeated measures ANOVA with a Tukey's multiple-comparison test). (C) Representative cytokine secretion levels observed at day 5 for human T cells exposed ex vivo to cell expansion conditions. Cytokine secretion profiles observed for each of 5 T cell donors ( $n=2$, 1-way ANOVA with Dunnett's test). TACs, tetrameric antibody complexes; i $\alpha$ CD3, immobilized anti-CD3; $s \alpha C D 28$, soluble anti-CD28. ${ }^{*} P$ $<0.05 ;{ }^{* *} P<0.01 ; \square$, T-CEP; O, TACs; $\diamond, \mathrm{i} \alpha \mathrm{CD} 3+\mathrm{s} \alpha \mathrm{CD} 28 ; \triangle, \mathrm{i} \alpha \mathrm{CD} 3$.

Similar phenotypic changes were observed in the T-CEP-treated $\mathrm{CD} 8^{+} \mathrm{T}$ cell population after 12 days, where the more differentiated $\mathrm{CD} 45 \mathrm{RA}^{+} \mathrm{CD} 27^{-} \mathrm{T}$ cells made up on average $1.8 \%$ of the population in the 5 donors, and the CD45RA-CD27- $\mathrm{T}$ cell population accounted on average for $22.8 \%$ of total $\mathrm{CD} 8^{+} \mathrm{T}$ cells (Figure $6 \mathrm{C}$ ). In comparison, treatment with TACs led to an average of $36.1 \%$ of $\mathrm{CD} 8^{+} \mathrm{T}$ cells having a CD45RA-CD27 phenotype. Out of these 2 soluble activators, only T-CEP significantly reduced this phenotype in the CD8 ${ }^{+}$ T cell population as compared with i $\alpha \mathrm{CD} 3$ with s $\alpha \mathrm{CD} 28(52.0 \%, P<0.05)$ or i $\alpha \mathrm{CD} 3$ alone $(52.5 \%, P<$ 0.05). For the T-CEP-stimulated $\mathrm{T}$ cells, this reduction in the CD45RA-CD27- phenotype appeared to shift more toward $\mathrm{CD} 27^{+}$phenotypes, as the less differentiated $\mathrm{CD} 45^{+} \mathrm{CD} 27^{+}$and $\mathrm{CD} 45 \mathrm{RA}-\mathrm{CD} 27^{+}$populations were highest in T-CEP-treated $\mathrm{T}$ cells, with a mean population percentage of $24.6 \%$ and $50.7 \%$, respectively (Figure 6C). This percentage of $\mathrm{CD} 45 \mathrm{RA}^{-} \mathrm{CD} 27^{+} \mathrm{T}$ cell subset was significantly increased as compared with cells stimulated with $\mathrm{i} \alpha \mathrm{CD} 3$ alone $(26.9 \%, P<0.001)$ or i $\alpha \mathrm{CD} 3$ with $\mathrm{s} \alpha \mathrm{CD} 28(33.8 \%, P<0.01)$. As seen with the $\mathrm{CD} 4^{+}$population, the TAC-treated samples also had increased levels of $\mathrm{CD} 45 \mathrm{RA}^{-} \mathrm{CD} 27^{+} \mathrm{T}$ cells, but again to a lesser extent than observed with T-CEP (Figure 6C).

The number of transferred $\mathrm{CD} 8^{+} \mathrm{CD} 27^{+} \mathrm{T}$ cells has previously been associated with an improved patient response to the adoptive therapy treatment using autologous TILs for metastatic melanoma (2). Stimulation with T-CEP increased the number of $\mathrm{CD} 8^{+} \mathrm{CD} 27^{+} \mathrm{T}$ cells relative to the other methods of stimulation for each of the 5 donors (Figure $6 \mathrm{D}$ ), with a mean frequency of $\mathrm{CD} 8^{+} \mathrm{CD} 27^{+}$cells representing $62.3 \%$ of the viable lymphocyte population on day 12 . This percentage was significantly greater than the proportion of such cells observed under other expansion conditions (i $\alpha \mathrm{CD} 3,34.3 \%, P<0.01$; i $\alpha \mathrm{CD} 3$ and $\mathrm{s} \alpha \mathrm{CD} 28,37.3 \%, P<0.01$; TACs, $38.1 \%, P<0.01)$. This elevated population of $\mathrm{CD} 8^{+} \mathrm{CD} 27^{+}$ 
A

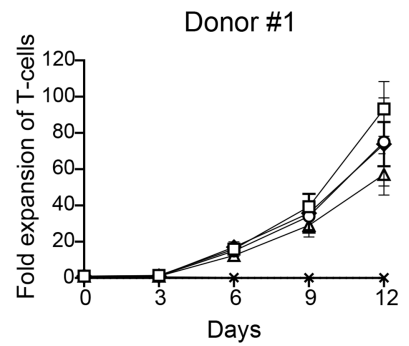

B

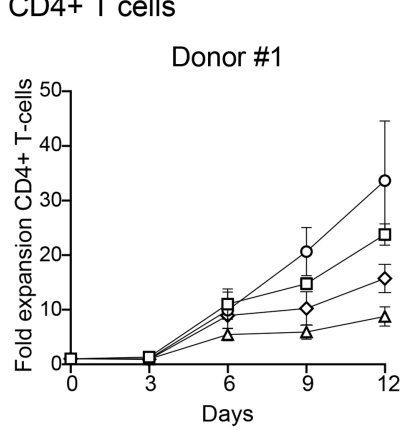

CD8+ T cells
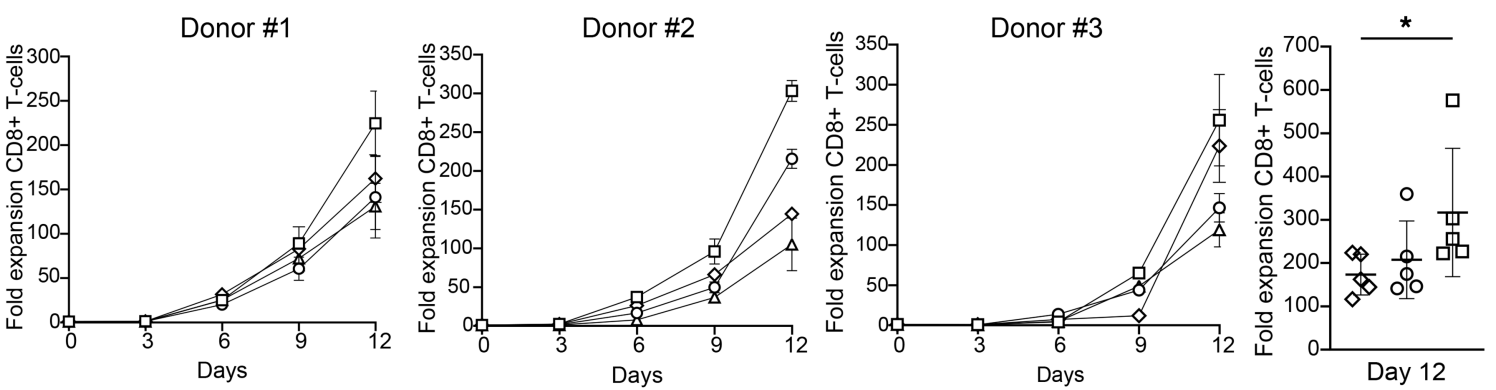

C

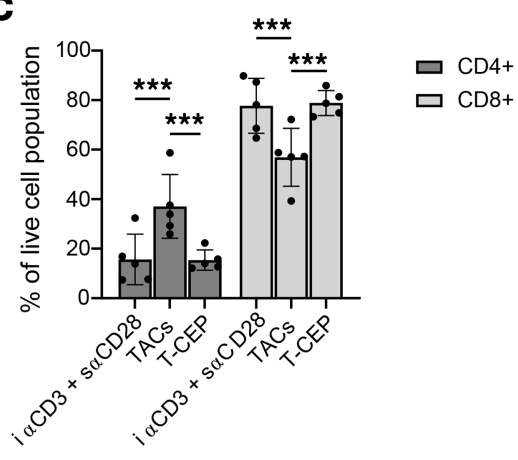

Figure 4. Monitoring the ex vivo expansion of activated human T cells over 12 days. (A) 12-Day expansion of purified human T cells from 5 PBMC donors, with representative expansion profiles of 3 donors. For each of the 5 donors, the number of viable cells was counted in duplicate samples using a hemocytometer following the staining of dead cells with trypan blue for each expansion method tested (right side, scatter plot). The average levels of T cell expansion were statistically greatest when T cells were treated with T-CEP, as compared with $\mathrm{i} \alpha \mathrm{CD} 3, \mathrm{i} \alpha \mathrm{CD} 3+\mathrm{s} \alpha \mathrm{CD} 28$, and TACs. ( $n$ = 5, 1-way repeated measures ANOVA, with a Tukey's multiple-comparison test.) (B) 12-Day expansion of CD4+ and CD8 ${ }^{+}$T cell subsets from purified T cells of 5 PBMC donors, along with individual expansion profiles of 3 representative donors. Scatter plots (right side) illustrate the effect of each treatment on the observed fold changes in the expansion of $C D 4^{+}$or $C D 8^{+} T$ cells for each of 5 donors. The fold expansion was calculated based on the starting number of $\mathrm{CD} 4^{+}$or $\mathrm{CD} 8^{+} \mathrm{T}$ cells. T-CEP treatment resulted in the highest fold expansion of CD8 $8^{+} \mathrm{T}$ cells $(n=5,1$-way repeated measures ANOVA with a Tukey's multiple-comparison test). (C) The percentage of activated human CD4+ and CD8 ${ }^{+} \mathrm{T}$ cell populations relative to the total number of viable lymphocytes as defined by flow cytometry following 12 days of culture. T-CEP or the combination of immobilized i $\alpha$ CD3 and soluble $s$ aCD28 mAbs favored the expansion of CD8 $8^{+}$human T cells significantly more than TACs. $(n=5,1$-way repeated measures ANOVA with a Tukey's multiple-comparison test.) TACs, tetrameric antibody complexes; i $\alpha$ CD3, immobilized anti-CD3; $5 \alpha C D 28$, Soluble anti-CD28. ${ }^{*} P<0.05 ;{ }^{*} P<0.01$; ${ }^{* * *} P<0.001 ; \square$, T-CEP; $O$, TACs; $\diamond, i \alpha C D 3+s \alpha C D 28 ; \triangle, i \alpha C D 3 ; x$, unstimulated. 
A
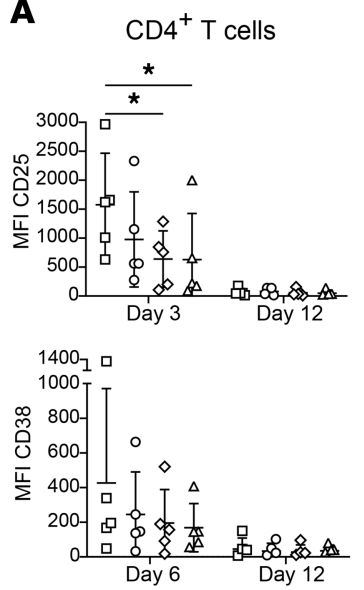
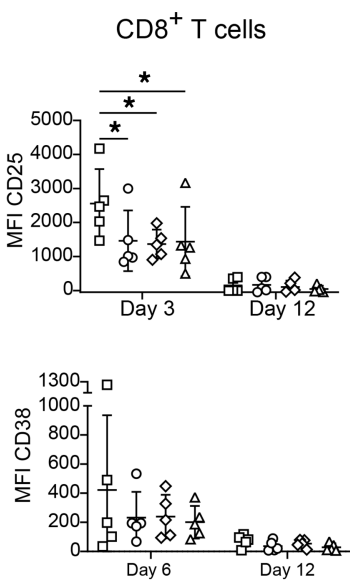

B
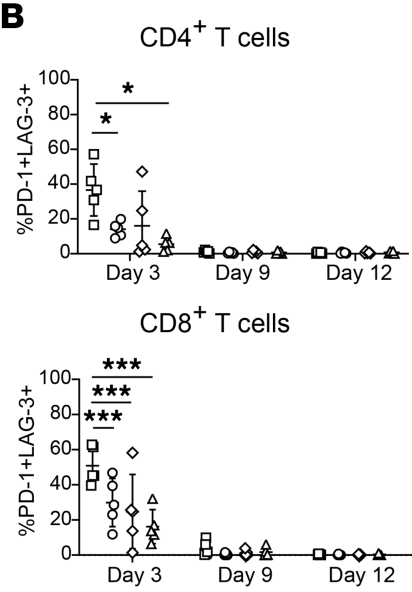

Figure 5. Human T cell activation following stimulation over a 12-day ex vivo expansion period. The presence of surface markers on human T cells from 5 donors was analyzed by flow cytometry. (A) The surface expression of activation markers CD25 and CD38 exposed to specific stimulation conditions. The increase in median fluorescence intensities (MFIs) for the activation markers was calculated by subtracting MFI values at day 0 before stimulation. MFI values of both activation markers decreased to baseline values by day 12 for all 3 donors. T-CEP-stimulated T cells showed the highest average expression of both activation markers. The MFI of CD25, significantly increased when stimulated with T-CEP as compared with i $\alpha$ CD3 and i $\alpha$ CD3 with s $\alpha$ CD28 in CD4+ T cells, and compared with i $\alpha$ CD3 in CD8 ${ }^{+}$T cells. There was no significant difference in peak CD38 MFI values between specific stimulation methods. By day 12 the MFI of both activation markers returned to pretreatment levels in all stimulation methods $(n=5$, 1-way repeated measures ANOVA with a Tukey's multiple-comparison test). (B) The coexpression of PD-1 and LAG-3 markers on human T cells peaked by day 3 and returned to pretreatment levels by day 12 . In both CD4 ${ }^{+}$and $C D 8^{+} T$ cells, the expression of these markers was significantly increased on day 3 in T-CEP-stimulated cells but returned to baseline values as in the case of other activation methods by day 9. ( $n=5$, 1-way repeated measures ANOVA with a Tukey's multiple-comparison test.) TACs, tetrameric antibody complexes; i $\alpha$ CD3, immobilized anti-CD3; s $\alpha$ CD28, soluble anti-CD28. ${ }^{*} P<0.05$; ${ }^{* * *} P<0.001$; $\square$, T-CEP; $\bigcirc$, TACs; $\diamond, \mathrm{i} \alpha C D 3+\mathrm{s} \alpha \mathrm{CD} 28 ; \triangle, \mathrm{i} \alpha \mathrm{CD} 3$.

$\mathrm{T}$ cells upon $\mathrm{T}$ cell expansion with T-CEP was independent of the T-CEP concentration over a $10 \mathrm{ng} /$ $\mathrm{mL}$ to $10 \mu \mathrm{g} / \mathrm{mL}$ range (54\%-78\% of total viable lymphocyte population), which contrasted with TACs (range of $23 \%-57 \%$ ) (data not shown). Higher expression of CD27 was consistently observed for CD ${ }^{+}$ $\mathrm{T}$ cells in the T-CEP-treated group in each donor on day 12, as demonstrated by the greater change in median fluorescence intensity $(\triangle \mathrm{MFI})$ of $\mathrm{CD} 27$ (mean $\triangle \mathrm{MFI} 1057$ ) relative to T cell groups treated with either i $\alpha C D 3$ (mean $\triangle$ MFI 407, $P<0.05$ ) or i $\alpha C D 3$ and $\mathrm{s} \alpha \mathrm{CD} 28$ (mean $\triangle \mathrm{MFI} 336, P<0.05$ ). This elevated CD27 expression compared with the immobilized methods was also observed in stimulation through TACs but with an average $\triangle \mathrm{MFI}$ of CD27, about half of what was observed through T-CEP stimulation (mean $\triangle \mathrm{MFI} 583$ ) (Figure $6 \mathrm{E}$ ). The fold expansion of $\mathrm{CD} 8^{+} \mathrm{CD} 27^{+} \mathrm{T}$ cells by day 12 for each donor $(n=5)$ was calculated using the percentage of $\mathrm{CD} 8^{+} \mathrm{CD} 27^{+}$cells derived from viable cells and the average total $\mathrm{T}$ cell count, relative to each donor initial $\mathrm{CD} 8^{+} \mathrm{CD} 27^{+} \mathrm{T}$ cell count. On average, T-CEP was found to increase the $\mathrm{CD} 8{ }^{+} \mathrm{CD} 27^{+} \mathrm{T}$ cell count by 325 -fold (range: 184-603) over 12 days, with the highest fold expansion in each donor. In comparison, i $\alpha C D 3$ (71-fold, range: $11-150, P<0.001$ ), i $\alpha$ CD3 and s $\alpha C D 28$ (110-fold, range: $44-185, P<0.01$ ), or TACs (172-fold, range: $65-330, P=0.05$ ) had a significantly lower amount after the 12-day expansion as determined for the 5 donors (Figure $6 \mathrm{~F}$ ).

\section{Discussion}

The ex vivo expansion of T cells through CD3 and CD28 pathways' coactivation is a common strategy for generating sufficient $\mathrm{T}$ cell products needed for ACT, although improvements to existing methods that would favor the expansion of fully functional $\mathrm{CD}^{+} \mathrm{T}$ cells are still needed. Existing protocols make use of immobilized CD3 and CD28 agonistic antibodies or ligands, presented typically on cells or beads. It has been reported that common ACT approaches where anti-CD3 and anti-CD28 are immobilized on magnetic beads favor the expansion of human $\mathrm{CD}^{+} \mathrm{T}$ cell subsets (16), which typically require sustained antigen exposure for growth $(31,32)$. Longer expansion times eventually favor the expansion of preferred human $\mathrm{CD}^{+} \mathrm{T}$ cells (33). However, methods that enrich for $\mathrm{CD} 8^{+} \mathrm{T}$ cells before expansion are clinically preferred because of the critical antitumor activity of $\mathrm{CD}^{+} \mathrm{T}$ cells (34). More recently, monospecific TACs have 

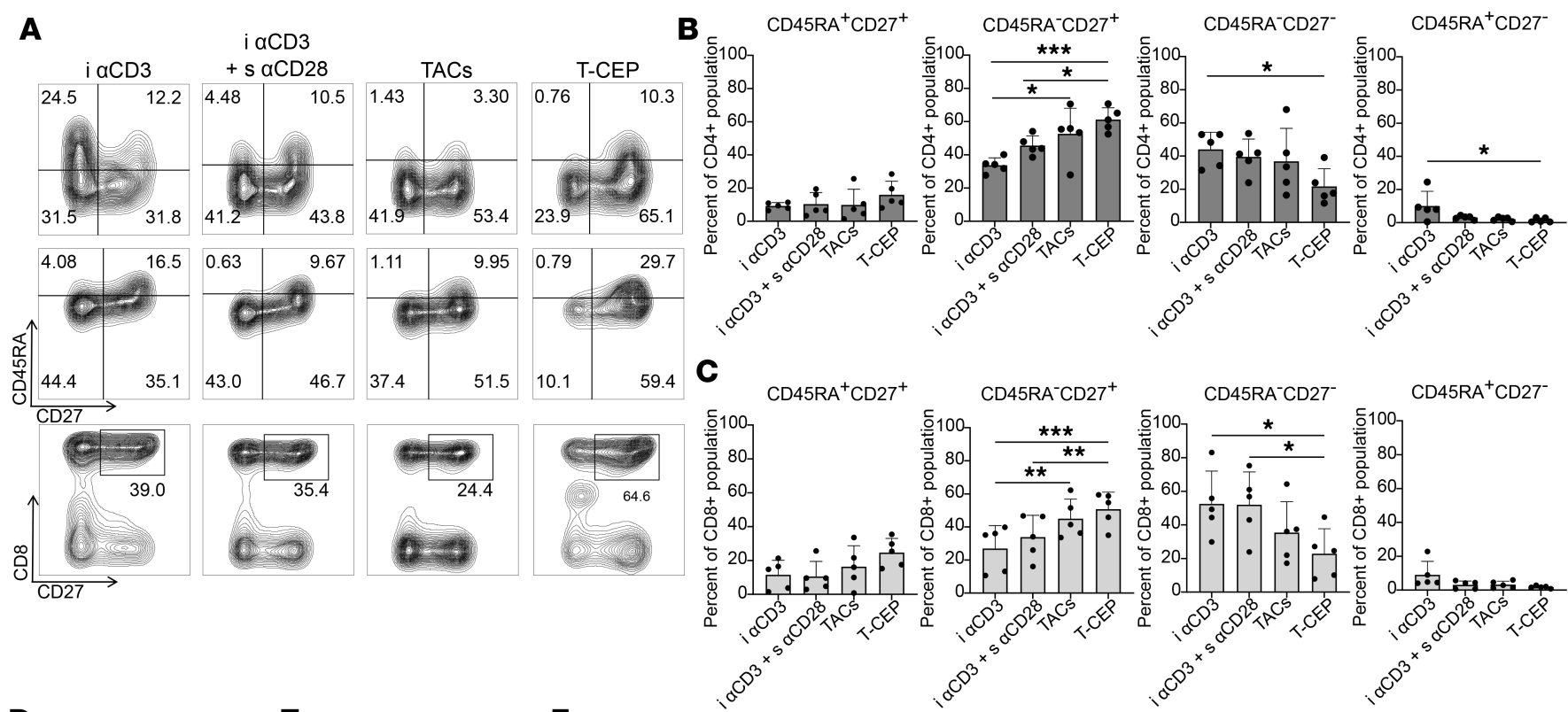

D

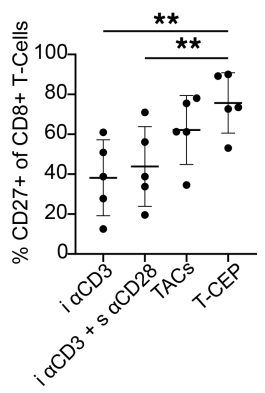

E

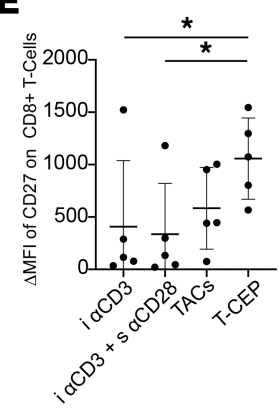

$\mathbf{F}$

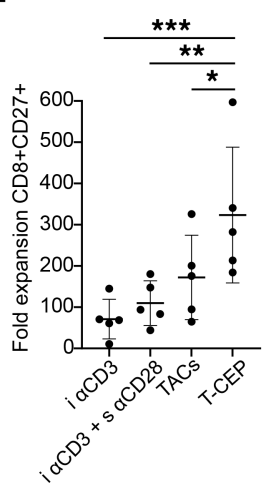

Figure 6. T-CEP favors the ex vivo differentiation of $T$ cells toward a less differentiated human CD8 ${ }^{+} \mathbf{T}$ cell phenotype. (A) Representative cytometric plots highlighting the expression of CD45RA and CD27 on CD4+ (top row) and CD8 (bottom row) T cells and of CD8 $8^{+}$CD27 human T cells at day 12 following their activation and expansion using a designated treatment. (B) Surface expression at day 12 of CD45RA and CD27 markers as a percentage of CD4+ populations from 5 donors. In the $\mathrm{CD}^{+} \mathrm{CD}^{+} \mathrm{T}$ cell subset population, T-CEP displayed significantly increased levels of CD45RA ${ }^{-} \mathrm{CD} 27^{+} \mathrm{T}$ cells relative to i $\alpha \mathrm{CD} 3$ treated cells with or without $s \alpha C D 28$. Additionally, T-CEP-stimulated T cells had the lowest percentage of CD45RA-CD27- and CD45RA ${ }^{+} \mathrm{CD}^{-} 7^{-}$phenotype, which were significantly reduced compared with i $\alpha C D 3$-treated T cells ( $n=5$, 1-way repeated measures ANOVA with a Tukey's multiple-comparison test). (C) Surface expression at day 12 of CD45RA and CD27 markers as a percentage of CD8 ${ }^{+}$populations from 5 donors. On average, T-CEP-stimulated T cells displayed the highest percentage of CD45RA-CD27 phenotype, with a significant increase relative to i $\alpha$ CD3 and i $\alpha$ CD3 with s $\alpha$ CD28. T-CEP also significantly reduced the CD45RA-CD27- T cell phenotype relative to i $\alpha$ CD3 with or without $5 \alpha C D 28$ ( $n=5$, 1-way repeated measures ANOVA with a Tukey's multiple-comparison test). (D) The percentage of viable CD8+CD27+ lymphocytes at day 12 observed in human T cell samples collected from 5 donors. T-CEP-stimulated T cells coexpressing CD8 and CD27 accounted for $62.3 \%$ of the total viable lymphocyte population, which was significantly higher compared with cells stimulated with $\mathrm{i} \alpha \mathrm{CD} 3$ alone, $\mathrm{i} \alpha \mathrm{CD} 3$ and $\mathrm{s} \alpha \mathrm{CD} 28$, and TACs ( $n=5$, 1-way repeated measures ANOVA with a Tukey's multiple-comparison test). (E) CD27 expression on CD8 ${ }^{+} \mathrm{T}$ cells $(\triangle \mathrm{MFI}$ ) at day 12 from each treatment modality. The $\triangle \mathrm{MFI}$ was calculated by subtracting the MFI value of the appropriate isotype control. The subset of $C D 8^{+} T$ cells expressing $C D 27$ was significantly higher in $T$ cells stimulated with T-CEP relative to $i \alpha C D 3$ or $i \alpha C D 3$ and $\mathrm{s} \alpha \mathrm{CD} 28$ ( $n=5$, 1-way repeated measures ANOVA). (F) The expansion of the $C D 8{ }^{+} \operatorname{CD} 27^{+}$T cells over 12 days was substantially greater when treated with T-CEP than with the other indicated stimulation methods ( $n=5$, 1-way repeated measures ANOVA with a Tukey's multiple-comparison test). TACs, tetrameric antibody complexes; i $\alpha C D 3$, immobilized anti-CD3; s $\alpha$ CD28, soluble anti-CD28. ${ }^{*} P<0.05 ;{ }^{* *} P<0.01 ;{ }^{* *} P<0.001$.

been employed as soluble T cell activators. However, we show here that TACs provide a reduced ability to expand $\mathrm{CD}^{+} \mathrm{T}$ cells that are clinically needed for successful ACTs.

We designed a simple soluble factor, termed T-CEP, that simultaneously delivers agonistic signals to both CD3 and CD28 on human T cells (Figure 1 and Figure 2). Structurally, T-CEP is a bispecific protein composed of a linear arrangement of $2 \mathrm{scFv}$ domains that agonize CD3 and CD28, respectively. The use of T-CEP results in the enhanced expansion of nonterminally differentiated human $\mathrm{T}$ cells that contrast with existing CD3/CD28 activation methods (Figure 3, Figure 4, Figure 5, and Figure 6). Specifically, T-CEP binds to recombinant human $\mathrm{CD} 3$ and $\mathrm{CD} 28$ with low nanomolar binding constants (Table 1) and as a soluble factor 
can activate both human $\mathrm{CD}^{+}$and $\mathrm{CD} 8^{+} \mathrm{T}$ cells at concentrations in the $\mathrm{fM}$ range $(10 \mathrm{ng} / \mathrm{mL}$ or less) relative to other known soluble CD3/CD28 agents (typically $\mu \mathrm{g} / \mathrm{mL}$ range; Figure 3). Human T cells stimulated with T-CEP and cultured for 5 days, without additional added cytokines, are able to induce their proliferation and cytokine secretion at levels similar to or higher than soluble TACs, but at a concentration $(10 \mathrm{ng} / \mathrm{mL})$ that is at least 150 -fold less than TACs $(1.5 \mu \mathrm{g} / \mathrm{mL}$; Figure 3$)$.

T-CEP demonstrates a preference for expanding $\mathrm{CD}^{+} \mathrm{T}$ cells as compared with TACs. This phenomenon is not yet understood. It has previously been shown that the transient stimulation of human $\mathrm{T}$ cells ex vivo favors the expansion of human $\mathrm{CD}^{+} \mathrm{T}$ cells, including when $\mathrm{i} \alpha \mathrm{CD} 3$ and anti-CD28 on beads are removed after 24 hours and cells are expanded for 14 days (17). The removal of the i $\alpha C D 3$ could explain in part why the expansion of human T cells may be skewed toward the production of $\mathrm{CD} 8^{+} \mathrm{T}$ cells after 12 days of expansion. The observed T-CEP biasing toward the expansion of human $\mathrm{CD}^{+} \mathrm{T}$ cells may reflect the degradation of T-CEP and its dilution (day 3 ) in the medium as its activation of human $\mathrm{T}$ cells requires concentrations above $1 \mathrm{ng} / \mathrm{mL}$. It is also possible that differences in strength or duration of interactions involving CD3 and CD28 are responsible for this difference.

Obtaining less differentiated $\mathrm{CD} 8^{+} \mathrm{T}$ cells after expansion has been of particular interest for ACT (13), as they have demonstrated superior antitumor immunity in vivo $(35,36)$. Human $\mathrm{T}$ cells can be further characterized along their differentiation pathways, from less differentiated subsets, such as Tn, Tscm, or Tcm cells, to more differentiated phenotypes, such as Tem or Temra cell populations $(13,14)$. Importantly, $T$ cell subsets at later stages of differentiation display a decline in IL-2 production and downregulate surface markers, such as CD27, CD28, CCR7, CD127, and CD62L $(37,38)$. Tracking such markers on T cells provides molecular signatures as to the state of differentiation of $\mathrm{T}$ cell populations. In particular, the surface expression of CD45RA and CD27 on human T cells collected from 5 donors was measured to estimate their state of differentiation following their ex vivo expansion with T-CEP and other activation methods. The expression of these markers on $\mathrm{T}$ cells has been established in the past with the least differentiated phenotypes being CD45RA ${ }^{+} \mathrm{CD} 27^{+}$(Tscm-like) and CD45RA-CCD27+ (Tcm-like or early Tem) and the

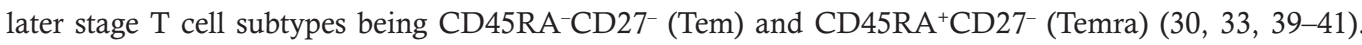
T-CEP-expanded human T cells exhibited a distinct $\mathrm{CD} 27^{+}$cell population in both their $\mathrm{CD} 8^{+}$and $\mathrm{CD} 4^{+} \mathrm{T}$ cell subsets (Figure 6). These $\mathrm{CD} 8^{+} \mathrm{CD} 27^{+} \mathrm{T}$ cells were primarily Tcm-like, as $\mathrm{CD}^{+} \mathrm{CD} 45 \mathrm{RA}^{-} \mathrm{CD} 27^{+}$cells represented the highest percentage of cells present at day 12 (Figure $6 \mathrm{C}$ ). Also, this level of $\mathrm{CD} 8^{+} \mathrm{CD} 27^{+}$ $\mathrm{T}$ cells in the final T-CEP-expanded product (62.3\%) was not observed with other expansion methods (Figure 6D), with a significantly high $\mathrm{CD} 8^{+} \mathrm{CD} 27^{+}$fold change expansion that was greatest in each of the 5 PBMC donors tested (Figure 6F). Overall, T-CEP led to a focused expansion of less differentiated Tcm-like $\mathrm{CD}^{+} \mathrm{CD} 45 \mathrm{RA}^{-} \mathrm{CD} 27^{+}$and Tscm-like $\mathrm{CD} 8^{+} \mathrm{CD} 45 \mathrm{RA}^{+} \mathrm{CD} 27^{+}$cells. This phenotype appeared to arise from a combination of a high level of CD27 expression along with a preferred CD $8^{+} \mathrm{T}$ cell expansion.

The ex vivo expansion features for T-CEP are clinically relevant, as $\mathrm{CD} 8^{+} \mathrm{Tcm}$ cells have previously been demonstrated to be superior to late-stage differentiated T cell subsets in ACT $(35,42)$. For instance, the persistence of melanoma-reactive T cells in patients with metastatic melanoma receiving ACT has been associated with their expression of CD27, suggesting a linkage between this differentiation marker and antitumor memory CD8 ${ }^{+} \mathrm{T}$ cells (27). Based on clinical outcomes observed in melanoma patients treated with TILs, the $\mathrm{CD}^{+} / \mathrm{CD}^{+}$ratio and the number of $\mathrm{CD} 8^{+} \mathrm{CD} 27^{+} \mathrm{T}$ cells infused in these patients correlated with their response to treatment $(2,43)$. Moreover, it was shown recently that the frequency of $\mathrm{CD}_{4} \mathrm{RO}^{-} \mathrm{CD} 27^{+} \mathrm{CD} 8^{+}$ $\mathrm{T}$ cells in the expanded CAR $\mathrm{T}$ cell product infused in patients with multiple myeloma was associated with their clinical response (44). CD27 is a costimulatory receptor that promotes $\mathrm{T}$ cell survival and memory $\mathrm{T}$ cell expansion $(45,46)$. The loss of this receptor on $\mathrm{T}$ cells is a marker for terminal differentiation $(39,47)$. $\mathrm{T}-\mathrm{CEP}$ consistently favors the ex vivo expansion of $\mathrm{CD} 8^{+} \mathrm{CD} 27^{+} \mathrm{T}$ cells after 12 days of expansion in medium supplemented with IL-2, conditions that mimic those used in ACT. A potent small recombinant protein, such as T-CEP, could provide an alternative method for expanding with minimal efforts (a single dose) a more desirable, less differentiated $\mathrm{CD} 27^{+} \mathrm{CD}^{+} \mathrm{T}$ cell population as part of an ACT protocol. A rationale explaining why T-CEP potently expands human $\mathrm{T}$ cells at low concentrations while skewing their differentiation pattern toward mostly $\mathrm{CD} 8{ }^{+} \mathrm{CD} 27^{+} \mathrm{T}$ cells remains elusive. Structurally, T-CEP is a soluble, monomeric, 60 $\mathrm{kDa}$, bispecific protein that engages both CD3 and CD28 through the action of 2 small scFvs linked by a short flexible spacer. As such, it may cross-link or promote the spatial rapprochement of human $\mathrm{T}$ cells expressing both markers. The molecular presentation of both CD3/CD28 agonists in T-CEP is also fixed at a molar ratio of $1: 1$. Its overall geometry differs from monospecific CD3/CD28 antibodies' TACs, the only other known 
soluble T cell activator delivering these signals. Although it was not further investigated, the nature of the scFvs agonizing CD3 and CD28, respectively, may explain why T-CEP works at low concentrations leading to a distinct pattern of $\mathrm{T}$ cell differentiation. Combining T-CEP with cytokines, such as IL-7 and IL-15, may further skew human T cells toward less differentiated phenotypes, such as $\mathrm{CD} 8^{+} \mathrm{Tcm}(48)$.

From a practical perspective, T-CEP is a smaller soluble protein than TACs. It is produced well in eukaryotic cells, and less of it is required for its application in expanding human $\mathrm{T}$ cells ex vivo. Further investigation on the use of T-CEP in ACT appears warranted based on its ability to expand a T cell phenotype desirable for ACT.

\section{Methods}

Recombinant protein expression and purification. T-CEP is a bispecific, monomeric protein construct composed of 2 agonistic scFvs that bind to human CD3 and human CD28, respectively, which are linked together through a short flexible spacer (Figure 1A). Specifically, a synthetic gene was assembled that coded for a human CD28 $\mathrm{scFv}$ followed by a CD3-binding scFv and a C-terminal His6-tag. The gene was synthesized to include distinct glycine-rich linkers between the VH and VL (GGGGSGGGGSGGGGS between anti-CD28 scFv VH and VL; GGSGGSGGSGGSGG between anti-CD3 scFv VH and VL) and a short spacer (SSGSGGGGSGGGGSGGGGS) linking the $2 \mathrm{scFv}$ domains. The final construct was cloned into a pcDNA-3.4 expression plasmid with a 5' Igא leader sequence for high protein secretion in the Expi293F cells (Thermo Fisher Scientific) in the Expi-293 mammalian cell expression system (Thermo Fisher Scientific). T-CEP was purified using HisTrap HP columns (GE Healthcare) and desalted using PD-10 columns (GE Healthcare). Protein purity was assessed by SDS-PAGE and by Western blot analyses (murine anti-polyHistidine-mAb [clone His-1] peroxidase conjugate; MilliporeSigma). The concentration of the protein was quantified using A280 measurement with the extinction coefficient calculated based on sequence (ProtParam; ExPASy). Approximately $25 \mathrm{mg}$ of purified T-CEP was recovered per liter of culture medium.

Surface plasmon resonance. The binding of T-CEP to the extracellular domains of human CD3 and CD28 was determined by SPR (Biacore T200, GE Healthcare). Briefly, protein G-coated CM5 chips (GE Healthcare) were used to capture human recombinant hIgG1-tagged CD28 (P10747-1) and hIgG1-tagged CD3E $\delta$ (Cambridge Biologics). Each target protein was injected at a flow rate of $10 \mu \mathrm{L} / \mathrm{min}$ for 60 seconds, and the capture was monitored in real time. The binding of T-CEP to either CD3 or CD28 was measured using an increasing concentration gradient of $0.25,0.5,1,2,4 \mathrm{nM}$ for T-CEP binding to recombinant CD3 and of $0.0625,0.125,0.25,0.5,1 \mathrm{nM}$ for T-CEP binding to recombinant CD28. T-CEP was injected with a flow rate of $30 \mu \mathrm{L} / \mathrm{min}$ for 120 seconds, with a dissociation time of 300 seconds for both targets. T-CEP binding to a control lane coated with protein $\mathrm{G}$ without any captured target protein was also calculated and subtracted from the active lane. No binding was observed in the control lane (data not shown). The resulting curve was fitted using a 1:1 Langmuir binding model. All reagents were diluted in $\mathrm{HBS}_{-} \mathrm{EP}^{+} \mathrm{pH} 7.4$ buffer (0.01 M HEPES, 0.15 M NaCl, 3 mM EDTA, 0.005\% Tween-20). The chip was regenerated using a Biacore Regeneration solution ( $\mathrm{pH}$ 1.7) (GE Healthcare) after each dissociation step.

ELISA-based measurements of T-CEP binding simultaneously to CD3 and CD28 extracellular domains. High-protein binding polystyrene ELISA plates (Corning) were coated overnight at $4^{\circ} \mathrm{C}$ with $\mathrm{hIgG1}$-tagged $\mathrm{CD} 3 \mathrm{E}^{\circ}$ (Cambridge Biologics) or a human IgGla-tagged VISTA-IgV domain (negative control) $(49)(4 \mu \mathrm{g} / \mathrm{mL})$ dissolved in PBS. Wells of plates were blocked with $1 \% \mathrm{w} / \mathrm{v}$ BSA (MilliporeSigma) for 1 hour at room temperature. T-CEP $(10 \mu \mathrm{g} / \mathrm{mL})$ was then dispensed in each well and incubated for 1 hour. The wells were washed with PBS, and biotinylated human recombinant hIgG1-tagged CD28 (P10747-1) was added to the wells for 1 hour, then detected using streptavidin-HRP (BioLegend) and TMB (Thermo Fisher Scientific). Human recombinant hIgG1-tagged CD28 was biotinylated using EZ-Link Sulfo-NHS-LC-Biotin (Thermo Fisher Scientific).

$T$ cell retrieval from human PBMCs. Human PBMCs were isolated from blood samples of 5 healthy donors using a Ficoll gradient. The recovery of $\mathrm{CD}^{+}$human $\mathrm{T}$ cells was then achieved using an EasySep Human $\mathrm{T}$ Cell Isolation Kit (STEMCELL Technologies). T cells were then seeded in a 96-well plate at a density of $5 \times$ $10^{5}$ cells/mL in X-VIVO 10 (Lonza) Hematopoietic Cell Medium supplemented with 5\% fetal bovine serum.

$T$ cell proliferation and cytokine secretion. For immobilized $\mathrm{T}$ cell activation, 96-well plates were coated with anti-CD3 (OKT3 Bio X Cell) at $4^{\circ} \mathrm{C}$ overnight. Wells were then washed 3 times with PBS before seeding cells. Soluble anti-CD28 (9.3 Bio X Cell) and soluble activators were added upon seeding. ImmunoCult Human CD3/CD28 TAC soluble activator (STEMCELL Technologies) was used according to the manufacturer's protocol to deliver anti-CD3 and anti-CD28 in TACs. The estimated concentration of $1.5 \mu \mathrm{g} / \mathrm{mL}$ for the TACs was calculated based on absorbance measurements recorded at $280 \mathrm{~nm}$. 
For measuring the expansion of initially proliferating cells, isolated human $\mathrm{CD}^{+} \mathrm{T}$ cells were labeled with CFSE following the manufacturer's protocol (Thermo Fisher Scientific). After 5 days, T cells were harvested and analyzed by flow cytometry (BD LSR II, BD Biosciences). The levels of IL-2, IFN- $\gamma$, and TNF- $\alpha$ secreted in the medium were quantified using a LEGENDplex multianalyte flow assay kit (BioLegend).

12-Day expansion protocol. For the 12-day expansion period, cells were directly seeded into a 96-well plate, and the medium was supplemented with $100 \mathrm{IU} / \mathrm{mL}$ recombinant human IL-2 (STEMCELL Technologies). Cells were then transferred to 24-well G-rex plates (Wilson Wolf). Aliquots of $10 \mu \mathrm{L}$ were taken from duplicate wells for counting using a hemocytometer and for flow cytometry except for day 3, when 2 wells representative of each stimulation method were used. The medium containing $100 \mathrm{IU} / \mathrm{mL}$ IL-2 was replenished every 3 days. To calculate changes in MFI signals, values recorded for CD25 and CD38 on day 0 , before stimulation, were subtracted from the MFI measurements taken every 3 days. The MFI value of the appropriate isotype control was subtracted from the MFI signal recorded for CD27 expression, to calculate the change in CD27-related MFI signals.

Flow cytometry. T cells collected from duplicate wells were combined and stained with appropriate antibody conjugates for 30 minutes at $4^{\circ} \mathrm{C}$, then washed and resuspended in $30 \mathrm{nM}$ DAPI prepared in PBS. Cell populations were subsequently analyzed by flow cytometry (BD LSR II).

Antibody conjugates, Alexa Flour 647-anti-CD8 (RPA-T8), PE/Cy7-anti-CD4 (OKT4), Alexa Flour 700-anti-CD25 (BC96), FITC-anti-CD38 (HIT2), PE-anti-PD-1 (EH12.2h7), PerCP-Cy5.5-anti-LAG3 (11C3C65), Dazzle-anti-CD27 (0323), and APC/Cy7-anti-CD45RA (HI100), and appropriate isotype controls were purchased from BioLegend. DAPI was bought from Thermo Fisher Scientific.

Statistics. Statistical analyses were performed using Prism 8 (GraphPad). A $P$ value of less than 0.05 was considered significant. The statistical significance between more than 2 groups was determined using a 1-way ANOVA or a repeated measures ANOVA with multiple-comparison tests. Data in figures represent mean \pm SD.

Study approval. Human blood samples were collected with the informed consent of donors for approved use of donors' blood for research (project identification number 443-2017), carried out in accordance with the guidelines set forth by Sunnybrook Health Sciences Research Ethics Board (Sunnybrook Research Institute, Toronto, Ontario, Canada).

\section{Author contributions}

EM and JG conceptualized the project and wrote the paper. EM performed and designed experiments and analyzed data. AS provided critical guidance for experimental studies.

\section{Acknowledgments}

This work was financially supported by project grants from the Canadian Institutes of Health Research to JG. EM is the recipient of a Queen Elizabeth II Graduate Scholarships in Science and Technology Award. The authors would like to thank Aaron Prodeus for his part in construct design. Furthermore, the authors would like to acknowledge the nurses at the Sunnybrook transfusion medicine clinic and the blood donors for their contribution.

Address correspondence to: Jean Gariépy, Physical Sciences, Sunnybrook Research Institute, room M7-434, 2075 Bayview Avenue, Toronto, Ontario M4N 3M5, Canada. Email: jean.gariepy@utoronto.ca.

1. Met Ö, Jensen KM, Chamberlain CA, Donia M, Svane IM. Principles of adoptive T cell therapy in cancer. Semin Immunopathol. 2019;41(1):49-58.

2. Rosenberg SA, et al. Durable complete responses in heavily pretreated patients with metastatic melanoma using T-cell transfer immunotherapy. Clin Cancer Res. 2011;17(13):4550-4557.

3. Zacharakis $\mathrm{N}$, et al. Immune recognition of somatic mutations leading to complete durable regression in metastatic breast cancer. Nat Med. 2018;24(6):724-730.

4. Holstein SA, Lunning MA. CAR T-cell therapy in hematologic malignancies: a voyage in progress. Clin Pharmacol Ther. 2020;107(1):112-122.

5. Rosenberg SA, Restifo NP, Yang JC, Morgan RA, Dudley ME. Adoptive cell transfer: a clinical path to effective cancer immunotherapy. Nat Rev Cancer. 2008;8(4):299-308.

6. Phan GQ, Rosenberg SA. Adoptive cell transfer for patients with metastatic melanoma: the potential and promise of cancer immunotherapy. Cancer Control. 2013;20(4):289-297.

7. Li D, et al. Genetically engineered T cells for cancer immunotherapy. Signal Transduct Target Ther. 2019;4(1):35.

8. Smith-Garvin JE, Koretzky GA, Jordan MS. T cell activation. Annu Rev Immunol. 2009;27:591-619. 
9. Jiang X, et al. Adoptive CD8 ${ }^{+} \mathrm{T}$ cell therapy against cancer:Challenges and opportunities. Cancer Lett. 2019;462:23-32.

10. Li K, et al. Adoptive cell therapy with $\mathrm{CD}^{+} \mathrm{T}$ helper 1 cells and $\mathrm{CD} 8^{+}$cytotoxic $\mathrm{T}$ cells enhances complete rejection of an established tumour, leading to generation of endogenous memory responses to non-targeted tumour epitopes. Clin Transl Immunology. 2017;6(10):e160.

11. Gattinoni L, et al. Acquisition of full effector function in vitro paradoxically impairs the in vivo antitumor efficacy of adoptively transferred CD8+ T cells. J Clin Invest. 2005;115(6):1616-1626.

12. Crompton JG, Sukumar M, Restifo NP. Uncoupling T-cell expansion from effector differentiation in cell-based immunotherapy. Immunol Rev. 2014;257(1):264-276.

13. Klebanoff CA, Gattinoni L, Restifo NP. Sorting through subsets: which T-cell populations mediate highly effective adoptive immunotherapy? J Immunother. 2012;35(9):651-660.

14. Gattinoni L, Klebanoff CA, Restifo NP. Paths to stemness: building the ultimate antitumour T cell. Nat Rev Cancer. 2012;12(10):671-684.

15. Petersen CT, et al. Improving T-cell expansion and function for adoptive T-cell therapy using ex vivo treatment with PI3K $\delta$ inhibitors and VIP antagonists. Blood Adv. 2018;2(3):210-223

16. Li Y, Kurlander RJ. Comparison of anti-CD3 and anti-CD28-coated beads with soluble anti-CD3 for expanding human T cells: differing impact on CD8 T cell phenotype and responsiveness to restimulation. J Transl Med. 2010;8:104.

17. Kagoya Y, et al. Transient stimulation expands superior antitumor T cells for adoptive therapy. JCI Insight. 2017;2(2):e89580

18. Giannoni F, et al. Clustering of T cell ligands on artificial APC membranes influences $\mathrm{T}$ cell activation and protein kinase C theta translocation to the T cell plasma membrane. J Immunol. 2005;174(6):3204-3211.

19. O'Connor RS, et al. Substrate rigidity regulates human T cell activation and proliferation. J Immunol. 2012;189(3):1330-1339.

20. Judokusumo E, Tabdanov E, Kumari S, Dustin ML, Kam LC. Mechanosensing in T lymphocyte activation. Biophys J. 2012;102(2):L5-L7.

21. Bortoletto N, Scotet E, Myamoto Y, D’Oro U, Lanzavecchia A. Optimizing anti-CD3 affinity for effective T cell targeting against tumor cells. Eur J Immunol. 2002;32(11):3102-3107.

22. Lanzavecchia A, Sallusto F. Understanding the generation and function of memory T cell subsets. Curr Opin Immunol. 2005;17(3):326-332.

23. Chen X, Zaro JL, Shen WC. Fusion protein linkers: property, design and functionality. Adv Drug Deliv Rev. 2013;65(10):1357-1369.

24. Kokaji AI, inventor; STEMCELL Technologies Inc, assignee. Soluble antibody complexes for T cell or NK cell activation and expansion. US application number 62045591. September 4, 2014.

25. Law CL, et al. Expression and characterization of recombinant soluble human CD3 molecules: presentation of antigenic epitopes defined on the native TCR-CD3 complex. Int Immunol. 2002;14(4):389-400.

26. Dushek O, et al. Antigen potency and maximal efficacy reveal a mechanism of efficient T cell activation. Sci Signal. 2011;4(176):ra39.

27. Powell DJ, Dudley ME, Robbins PF, Rosenberg SA. Transition of late-stage effector T cells to CD27+ CD28+ tumor-reactive effector memory T cells in humans after adoptive cell transfer therapy. Blood. 2005;105(1):241-250.

28. Hamann D, et al. Evidence that human CD8+CD45RA+CD27- cells are induced by antigen and evolve through extensive rounds of division. Int Immunol. 1999;11(7):1027-1033.

29. Larbi A, Fulop T. From "truly naïve" to "exhausted senescent" T cells: when markers predict functionality. Cytometry A. 2014;85(1):25-35.

30. Di Mitri D, et al. Reversible senescence in human CD4+CD45RA+CD27- memory T cells. J Immunol. 2011;187(5):2093-2100.

31. Rabenstein H, et al. Differential kinetics of antigen dependency of CD4+ and CD8+ T cells. J Immunol. 2014;192(8):3507-3517.

32. Foulds KE, Zenewicz LA, Shedlock DJ, Jiang J, Troy AE, Shen H. Cutting edge: CD4 and CD8 T cells are intrinsically different in their proliferative responses. J Immunol. 2002;168(4):1528-1532.

33. Kaartinen T, et al. Low interleukin-2 concentration favors generation of early memory T cells over effector phenotypes during chimeric antigen receptor T-cell expansion. Cytotherapy. 2017;19(6):689-702.

34. Prieto PA, Durflinger KH, Wunderlich JR, Rosenberg SA, Dudley ME. Enrichment of CD8+ cells from melanoma tumor-infiltrating lymphocyte cultures reveals tumor reactivity for use in adoptive cell therapy. J Immunother. 2010;33(5):547-556.

35. Klebanoff CA, et al. Central memory self/tumor-reactive CD8+ T cells confer superior antitumor immunity compared with effector memory T cells. Proc Natl Acad Sci U S A. 2005;102(27):9571-9576.

36. Sommermeyer D, et al. Chimeric antigen receptor-modified $\mathrm{T}$ cells derived from defined CD $8+$ and CD4+ subsets confer superior antitumor reactivity in vivo. Leukemia. 2016;30(2):492-500.

37. Fritsch RD, Shen X, Sims GP, Hathcock KS, Hodes RJ, Lipsky PE. Stepwise differentiation of CD4 memory T cells defined by expression of CCR7 and CD27. J Immunol. 2005;175(10):6489-6497.

38. Mahnke YD, Brodie TM, Sallusto F, Roederer M, Lugli E. The who's who of T-cell differentiation: human memory T-cell subsets. Eur J Immunol. 2013;43(11):2797-2809.

39. Hamann D, et al. Phenotypic and functional separation of memory and effector human CD8+ T cells. J Exp Med. 1997;186(9):1407-1418.

40. Schiött A, Lindstedt M, Johansson-Lindbom B, Roggen E, Borrebaeck CA. CD27- CD4+ memory T cells define a differentiated memory population at both the functional and transcriptional levels. Immunology. 2004;113(3):363-370.

41. Callender LA, et al. Human CD8 ${ }^{+}$EMRA T cells display a senescence-associated secretory phenotype regulated by p38 MAPK Aging Cell. 2018;17(1):e12675.

42. Graef $\mathrm{P}$, et al. Serial transfer of single-cell-derived immunocompetence reveals stemness of CD8(+) central memory T cells Immunity. 2014;41(1):116-126

43. Huang J, et al. Modulation by IL-2 of CD70 and CD27 expression on CD8+ T cells: importance for the therapeutic effectiveness of cell transfer immunotherapy. J Immunol. 2006;176(12):7726-7735.

44. Cohen $\mathrm{AD}$, et al. B cell maturation antigen-specific CAR T cells are clinically active in multiple myeloma. J Clin Invest. 2019;129(6):2210-2221.

45. Hendriks J, Gravestein LA, Tesselaar K, van Lier RA, Schumacher TN, Borst J. CD27 is required for generation and long-term 
maintenance of T cell immunity. Nat Immunol. 2000;1(5):433-440.

46. Hendriks J, Xiao Y, Borst J. CD27 promotes survival of activated T cells and complements CD28 in generation and establishment of the effector T cell pool. J Exp Med. 2003;198(9):1369-1380.

47. Neeson P, et al. Ex vivo culture of chimeric antigen receptor T cells generates functional CD8+ T cells with effector and central memory-like phenotype. Gene Ther. 2010;17(9):1105-1116.

48. Cha E, Graham L, Manjili MH, Bear HD. IL-7 + IL-15 are superior to IL-2 for the ex vivo expansion of 4T1 mammary carcinoma-specific T cells with greater efficacy against tumors in vivo. Breast Cancer Res Treat. 2010;122(2):359-369.

49. Prodeus A, et al. VISTA.COMP - an engineered checkpoint receptor agonist that potently suppresses T cell-mediated immune responses. JCI Insight. 2017;2(18):94308. 